\title{
THE REFERENCE SYSTEM IN THE MODEL OF PGE: PROPOSING A GENERALIZED DESCRIPTION OF REFERENCE PRODUCTS AND THEIR INTERRELATIONS
}

\author{
Albers, Albert; Rapp, Simon; Spadinger, Markus; Richter, Thilo; Birk, Clemens; Marthaler, \\ Florian; Heimicke, Jonas; Kurtz, Victor; Wessels, Holger \\ Karlsruhe Institute of Technology (KIT)
}

\begin{abstract}
Samsung recently introduced a new smartphone display with increased breaking resistance, which will probably be relevant for future cars as well. This example shows that subsystems, in general artefacts from former development processes can be relevant for subsequent projects. Their integration has to be planned, i.a. even before the original product is in the market and across branches. The research on supporting methods requires a suitable description model for this phenomenon. Research in design reuse and PGE - product generation engineering addresses this only partially yet. Design reuse focuses on the informational aspect, PGE refers primarily to reference products. This contribution aims at closing this gap as a basis for future research. Two case studies from industry projects by the authors and an example from foresight and product planning show the role of artefacts from former development processes in running projects. It is described which artefacts are used as a reference, why they are used and when. Based on these findings the authors propose the term "reference system" to depict the whole set of artefacts, which serves as a basis for every product development project.
\end{abstract}

Keywords: Design theory, Ontologies, Knowledge management

\section{Contact:}

Albers, Albert

Karlsruhe Institute of Technology (KIT)

IPEK Institute of Product Engineering

Germany

albert.albers@kit.edu

Cite this article: Albers, A., Rapp, S., Spadinger, M., Richter, T., Birk, C., Marthaler, F., Heimicke, J., Kurtz, V., Wessels, H. (2019) 'The Reference System in the Model of PGE: Proposing a Generalized Description of Reference Products and their Interrelations', in Proceedings of the 22nd International Conference on Engineering Design (ICED19), Delft, The Netherlands, 5-8 August 2019. DOI:10.1017/dsi.2019.175 


\section{MOTIVATION}

Only recently, Samsung declared the development of a new display (Jwa, 2018). This way, upcoming smartphone product generations will have much more robust and thus unbreakable screens. But the new technology will not only be used for smartphones. The new displays could also be used in cars or for devices that are used outdoor. If so, this way of using the displays for one of the upcoming car product generations requires planning of the car manufacturer, before the corresponding smartphone product generations are available on the market. Integrating the new display technology with the rest of the car will then be an essential part of the development activities for the new car generation.

Thus, the example depicts on the one hand how technical systems can also influence product generation engineering across sectors. On the other hand, it is made clear that not only products available on the market play a role in planning own product generations but existing technical systems in general. In addition, it is underlined that it is not necessarily the entire product - in this case the smartphone - that is taken into consideration but in some cases only a selection of subsystems - like the display for example. Finally yet importantly, one can conceive that interrelations between subsystems from different sources can be a trigger for development activities, if these subsystems together are the basis for a new product generation.

To conduct such activities successfully, suitable methods and processes aim to support product developers. Investigating such methods and processes requires a suitable description model of the underlying phenomena as a foundation. In order to describe the phenomena mentioned above and make them accessible for research purposes this contribution proposes the "reference system" as an extension to the model of PGE - Product Generation Engineering. The basis are the research questions derived in section 3 .

\section{REUSE OF KNOWLEDGE AND SUBSYSTEMS IN PRODUCT DEVELOPMENT}

Product innovation is always a mix of successful "old" designs and new ones (Sivaloganathan and Shahin, 1999; Wyatt et al., 2009). According to estimates, only $20 \%$ of the components would have to be newly developed and $40 \%$ taken over (Iyer et al., 2005). Sources on which the developer has relied so far are his own experiences or projects known to him (Ahmed et al., 2003). According to Cross (2007), the majority of the engineering work lies in changing and modifying existing products. Especially when it is a complex task, the engineer tries to profit from the experiences of past projects (Shahin et al., 1999). The Case Based Reasoning approach provides methodical support for the use of Wierder (Maher and Garza, 1997). For a given problem, references are sought that solve a similar problem and thus provide incentives for the developer. In a similar way, the $\mathrm{C}-\mathrm{K}$ Theory makes it possible to find creative solutions (Hatchuel et al., 2004). The method first breaks down a complex problem into its attributes, to which analogies the experience/knowledge (Knowledge Space - K) of the developer is searched. These analogies are combined to solutions / concepts (Concept Space - C), which in turn cause analogies in the developer.

According to Gero's Design Prototypes scheme (1990), prototypes are created on the basis of previous designs. Gero also notes that the context in which the developer moves has to be considered, whether the new design, and in particular the creative design, can be described as a variation of already known solutions.

Design Reuse aims to reuse successful solutions from the past to reduce costs and increase flexibility in development (Eckert et al., 2004, Sivaloganathan and Shahin, 1999; Corso et al., 1999; Alblas and Jayaram, 2015). Reuse can take place on different levels - solution, design or physical level (Wouters and Kressens-van Drongelen, 2004). The greatest challenges in this area lie in the provision of the required information. The main tasks are to display, capture, organize and retrieve design information (Iyer et al., 2005; Shahin et al., 1999; Sivaloganathan and Shahin, 1999). "Design Reuse Systems" deal fundamentally with the methods by which information about past designs can be stored, retrieved, and used (Duffy et al., 1995). Accordingly, the system should contain a functional description of the concept, a function tree, a component structure as well as information on the design (drawing, CAD models, etc.), see also Design Function Deployment. This information can be found on different system levels of the Design Reuse System (Shahin et al., 1999). 
Duffy et al. describes a process for reuse. This is based on six so-called knowledge sources, which describe the origin of the knowledge. The process model describes the abstraction of knowledge from a knowledge source and its transfer into a new design (Duffy et al., 1998).

Engineering Change (EC) in turn describes the fact that a large part of engineering activity consists in the modification of existing products to new boundary conditions or due to errors - a distinction is made between internal and external causes of change (Martin and Ishii, 2002; Hatchuel et al., 2004, Eisa et al., 2018). EC are often divided into different categories. A frequently cited classification is that according to Eckert (Jarratt et al., 2002). Langer et al. (2012) only distinguishes between EC and critical EC.

These observations lead to product developments being described, among other things, as evolutionary, based on biological processes (Hubka and Ernst Eder, 1992). Mozgova transforms this description into a model of technical inheritance. The model describes the development on the basis of three mechanisms - mutation, selection and technical inheritance. The starting point for the next generation is thus the analysis of the information and knowledge generated in the previous generation. Not necessarily only the direct predecessor generation plays a role. (Mozgova et al., 2015)

In addition to the current available knowledge, the foresight of future developments is also necessary. To this end, the integrated use of methods of product development and strategic product planning is increasingly applied (Gausemeier and Plass, 2015). According to Fink and Siebe, apart from trends, especially technology and market environment scenarios are used for long-term planning horizons with an increasing time horizon (Fink and Siebe, 2016). The goal is to enable decisions under circumstances of uncertainty and about the resulting chances and risks.

The model of PGE - Product Generation Engineering - of ALBERS portrays fundamental observations on the development of new technical products. The model aims at the description of every form of product engineering and thus enabling the research and the development of methods for various kinds of engineering projects. The PGE-model is based on two basic assumptions (Albers, Bursac and Wintergerst, 2015).

Every product development is based on existing subsystem solutions or concepts - referred to as "reference products". Their structure and subsystems are either carried over in the engineering of new technical products or serve as a starting point for developing subsystems newly. The engineering of every new technical product is thus seen as the development of a new product generation, even if it is the first generation of a certain product. Reference products can be chosen from immediate predecessors of a product generation but also competitive products, products from different sectors, systems from R\&D projects or university research.

The development of the subsystems of a new product generation is done exclusively by three types of variation: During the carryover variation of a subsystem $(\mathrm{CV})$, the subsystem of a reference product is carried over and is, if necessary, only adjusted at the interfaces during the system integration. During the embodiment (EV) and the principle variation of a subsystem of a new product generation (PV), this subsystem is developed new, based on a selected subsystem of a reference product, starting with the variation of the embodiment or the principle, respectively.

The modeling of the processes and activities for the development of a new product generation is mapped in the iPeM - integrated product engineering model. In the iPeM, the development of different product generations, the validation system, the production system and the strategy is modelled in an integrated way, since these areas correlate strongly with their objectives (system of objectives), object system and action systems. (Albers et al., 2016b)

\section{AIM OF RESEARCH \& METHODOLOGY}

The sections above show different approaches to describe how new products build up on knowledge gained in previous development activities. These approaches have different scopes, for example, the creation of new technical concepts or changes in already existing system structures with a limited share of new development. The model of PGE provides an ontology, which aims at describing development projects in a wide range of new development shares and is therefore the basis in this work. The model element "reference product" refers to single existing technical systems, which are the basis and starting point for activities in the development of a new product generation.

The example from the introduction illustrates already, that the basis for the development of a new product generation can consist of several reference products. Furthermore, in some cases only subsystems of a reference product are of interest and not the entire product. Merging and adapting 
subsystems from different reference products in a new product generation requires, for example, overcoming initial incompatibilities. Thus, a trigger for development activities can be the interrelation between subsystems from different reference products. However, beyond the "reference product" the ontology of the PGE model provides no model element to depict a set of subsystems from different sources and their interrelations as basis and starting point for the development of a new product generation. Consequently, a basis is missing for researching and developing suitable methods and processes to support developers in handling such cases.

This work aims at closing this gap by proposing a new element in the model of PGE. The basis are observations made in three case studies by the authors. The analysis in the case studies and the proposal of the derived model element are led by the following questions:

- What artefacts from preceding technical systems can be observed as a basis and starting point for development activities within the case studies?

- Which interrelations are observable between those artefacts?

- How to cover set of these artefacts including their interrelations in one model element?

The first case study comes from a company that develops and produces machines for foam production. The second case study looks at the development of a new generation of machine tools. Third, the role of existing technical systems in product planning and foresight is described. In all three cases, the authors of this paper have direct access to the projects or activities and can therefore report directly. Based on the case studies, the model element "reference system" is proposed.

\section{THE REFERENCE SYSTEM IN PGE - PRODUCT GENERATION ENGINEERING}

\subsection{Case study: New technology for processing particle foam}

The object of this case study was the introduction of a new technology to process foam particles. For over 40 years, moulding machines have been developed to sinter, colloquially 'foam', foam particles in a press using compressed, hot saturated steam. The customers' requirement to foam new materials often failed due to safety risks. In most cases, these materials require a higher steam temperature. To achieve a higher steam pressure, which, in turn, leads to highly stressed machine parts which are unsafe and economically unacceptable. Additionally, the efficiency of the machine using steam is comparatively low and it is hardly possible to improve it. This is mainly due to thermal losses caused by heating and cooling the tool frames in which the material is sintered. The need to be able to foam new materials and the demand for a safer process with improved efficiency led to attempts to develop a new technology. Therefore, several attempts by different companies were made to process foam particles in a high-frequency (HF) electromagnetic (EM) field. Yet it was not successfully introduced to the market. Failures were often caused by the lack of know-how of a mechanical engineering company in dealing with high-frequency applications. This was systematically avoided in the investigated case study. In the following, it is explained how a process was developed by which a wide variety of materials can be processed using dielectric heating. To start the project, the patent of an uncompetitive company was examined, from which the functional principle - sintering foam particles using electromagnetic waves - is derived. Due to abandonment, this patent could be used without restriction for the company's own development. An expert in high-frequency technology from a company outside the industry was recruited for the development team with no prior know-how in processing particle foams. Two process engineers from the own company were added to the core of the team, providing many years of experience in the development of the preceding product generations. The cognitive distance within the team proved to be a positive factor for this project. However, some employees and managers had doubts concerning the technology development. In order to convince them of the functional principle, small material samples were sintered in a household microwave for demonstration purposes. Although the developers were aware that microwaves are not suitable for sintering larger geometries due to their wavelength, the tests were successful for the purpose mentioned. To produce moulded parts with homogeneous quality, larger wavelengths than the $12.2 \mathrm{~cm}$ used in microwaves are required to create a homogeneous electromagnetic field. There are official regulations, which frequencies may be used industrially, in this case the industrial scientific medical (ISM) band. Considering this, radio waves with a length of $11 \mathrm{~m}$ were selected. The development team knew of machines in which PVC foils are sealed using radio waves. These 
machines consist of a high-frequency (HF) generator, a C-press, which also represents the two electrodes for setting up an EM field, and a power adjustment which regulates the power of the generator. This design was used for initial tests and subsequently integrated points in the company's own development. The corresponding high-frequency generator was purchased for this purpose. The C-press and the power adjustment of the PVC machine are not suitable for the own process, because the requirements for the mentioned subsystems differ too much between the PVC machine and the particle foam machine. However, the tests on the PVC machine helped to create a knowledge base to design an own power adjustment which was needed for the construction of an own prototype. The design of the prototype focused on fast commissioning and the least necessary functionality. For this purpose, subsystems of the machines with steam process were used as carryover. The commissioning of the prototype posed three major challenges: Firstly, the simulation of the process thermic is difficult without experience of the behaviour of foam particles in an EM-field. By "educated guessing" the thermal behaviour during the process was calculated and tested on the example of simple geometries that could be produced in the prototype. Secondly, dielectric parameters of foam particles and tool materials are required to calculate the process parameters. Since these are not listed in the data sheets of the manufacturers in the temperature range of interest, a separate laboratory was set up in which the required characteristic parameters could be determined. The third challenge is the design of tools and electrodes, as these have a decisive influence on the quality of the sintered part. This influence results from the direct correlation between the design of these machine elements and the homogeneity of the resulting EM field. Adjustments of process parameters and tool materials in order to meet the three challenges just mentioned can only be carried out in separate steps since each adjustment has individual effects on the quality of the sintered part.

\subsection{Case study: The development of machine tools}

The object of another case study is the development of a generation of machine tools for the combined punching and laser processing of sheet metal in the entry-level segment. In the beginning the initial system of objectives focused on the development of a new punching machine. The aim was to keep the architecture of the machine - to the greatest possible extent - similar to the previous generations, keep the "C frame" and integrate a selection of new functions. In order to reduce manufacturing and operating costs, it was planned to replace the hydraulic punching head with an electrical powered punching head, that had already been developed within a separate predevelopment project. However, the tool holder within the punching head had not been changed. After initiating development activities and creating an engineering generation, the system of objectives was extended. The Sales department demanded a reduction of the installation area for the machine. The latter made it impossible to continue with the previous concept based on the $\mathrm{C}$ frame (cf. figure 1). To fulfil the specifications of the installation area, the concept of an "O frame" was adopted. This concept is considered as standard in the industry but had not been used by the manufacturer before. Within the following two engineering generations the system architecture was subsequently adapted to the new "O-frame" concept, the compatibility of interfaces was ensured and the integration of the existing electric punching head into the "O-frame" was evaluated. In addition, the existing programming system was adapted to the new architecture.

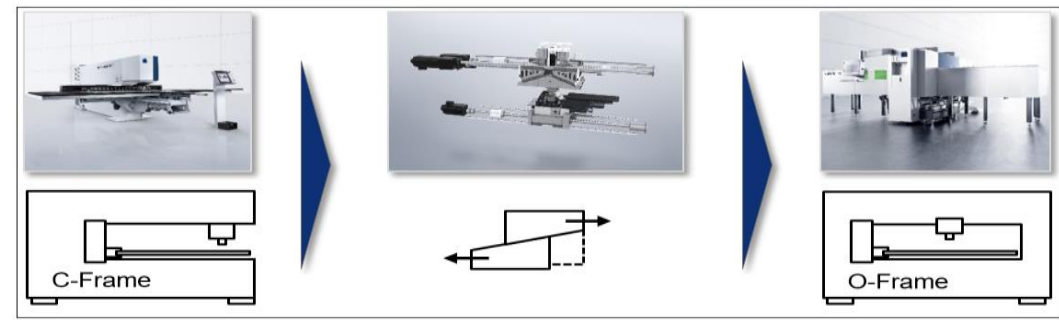

Figure 1: PGE of punching machines, frame concepts and wedge principle

At the same time, a new drive concept was developed in another predevelopment project. The new drive concept requires an "O frame" and allows the positioning of the punching unit as well as the release of the punching stroke by two electrical powered shafts - based on the principle of wedges that can be moved against each other. Since the prospects of success of the machine with the new drive were estimated higher than the current engineering generation with the existing electrical punching head, the system of objectives was adjusted yet again to pursue the development of the new drive 
concept. This decision again required extensive adjustments to the interfaces between the O-frame, the drive concept, the other machine components as well as the associated programming system. Shortly after, the development of an entry-level combined punch laser processing machine for sheet metal was initiated. To date, no such machine was listed in the portfolio of the manufacturer within the entry level. In the context of concept development, the team came up with the idea of upgrading the punching machine with the "O frame" - which was still in the stage of development - modularly by the necessary laser components. The machine could be available as a punching machine or as a combined punch laser processing machine depending on the actual configuration. Due to the similar requirements and the expected low development costs, the idea was pursued and further developed for series production. However, this also required a great deal of coordination to bring the two specifications into line and consider the respective technical requirements to enable a modular design and the associated variation in the function of the machines. Some subsystems however could be reused from other machines within the manufacturer's portfolio (e.g. laser cutting unit, control panel). Others had to be adapted to the new architecture by varying the principle and design (e.g. support tables, beam protection). Looking at the development period of the machine retrospectively, it becomes obvious that the predecessor machine, an existing electrical punching head and several predeveloped functions, were used as a basis for generation engineering. In response to the newly defined requirements, the established concept of the " $\mathrm{C}$ frame" was replaced by the concept of the "O frame" while a de facto industry standard served as the basis here. In addition, a new drive was introduced, that combines ball screws - which are used in rival products- and the principle of wedges which can be moved against each other. When adding laser components to the punching machine concept, subsystems from the existing machine portfolio of the manufacturer were used and adapted to the new machine concept. Due to the subsequent changes to the system of objectives of the products, adjustments had to be made to the architecture, the interfaces and the associated software products repeatedly. Although the selective takeover of existing components from the manufacturer's portfolio enabled significant cost savings, the dependencies between the components within the machine and within the portfolio increased significantly. For example, the built-in cutting unit must be able to withstand the vibrations caused by a punching stroke. At the same time, the installed electric motors must meet higher requirements regarding positioning accuracy and performance data to enable precise machining and be able to handle the additional mass caused by the cutting unit installation. An overview of the type of artefacts, their origin and their interactions within the case study is presented below:

Table 1: Artefacts, origin and interrelations in the case

\begin{tabular}{lll} 
Artefact & Origin & Interrelations \\
\hline Machine concept O frame & Portfolio, current generation & Automation solution \\
\hline Electric punching head & Predevelopment project, & Energy supply \\
\hline O frame & Industrial Standard & $\begin{array}{l}\text { Architecture of machine, } \\
\text { Interfaces to almost all subsystem, } \\
\text { programming system }\end{array}$ \\
\hline $\begin{array}{l}\text { Electric punching head, } \\
\text { principal of sliding wedges }\end{array}$ & $\begin{array}{l}\text { Predevelopment, known } \\
\text { principle }\end{array}$ & $\begin{array}{l}\text { architecture machine o frame, } \\
\text { programming system }\end{array}$ \\
\hline "O frame punching machine" & Current development without & $\begin{array}{l}\text { Requirements of punching and } \\
\text { combined machines, Interfaces } \\
\text { modular design }\end{array}$ \\
& market release & Interfaces to portfolio \\
\hline $\begin{array}{ll}\text { Operator panel, cutting unit } \\
\text { Support tables, beam } \\
\text { protection }\end{array}$ & $\begin{array}{l}\text { Takeover from Portfolio } \\
\text { way of realization }\end{array}$ & $\begin{array}{l}\text { Interactions between machine } \\
\text { concepts }\end{array}$
\end{tabular}

\subsection{Case Study: The role of existing systems in product planning and foresight}

Current approaches for product planning and foresight have in common that an initial Current Situation either the current product architecture or a previous product generation - has to be identified and analyzed (Albers et al., 2018). A study on this subject shows that the selection of the right product or the right architecture for the description of this initial Current Situation has an important influence on the success of the application of the different approaches: In this study, 12 experts on industrial practice that it is not enough to consider only the predecessor of a specific product generation as the reference (Marthaler et al., 2019). According to the experts' assessment, this leads only to an incremental 
continuation of currently established products and architectures on the market. Another study in this context - a delphi study - which was carried out by experts on industrial product development practice and foresight presents the importance of success factors in a system which integrates the use of methods of foresight into product engineering. The study emphasizes - based on the success factor prioritized by the experts - that the exclusive use of currently successful products and architectures on the market as references is not sufficient: „Die Systematik, muss den Anker der Gegenwart lösen, und das Blickfeld der Entwickler in die Zukunft richten!". ("The sytem has to weigh the anchor of the present and lead the developers' attention on the future!"). (Marthaler et al., 2019) This shows that the single discussion about today's solutions is not enough to generate creative solutions for tomorrow. The more the current product and the representation of future solutions differ, the more creative developers can be.

\subsection{The reference system as the basis of every product engineering project in the PGE model}

The following observations and deductions are taken from the cases:

- The development of a new product generation can be based on several existing technical systems but at least on one. This becomes clear from the examples of the foam case and the machine tool study.

- The underlying systems are not necessarily products in terms of being available on the market.

- From the mentioned technical systems, sometimes only selected subsystems are relevant for the development of a new product generation, like the machine frame of the machine tool for example.

- In addition, other objects, which are the result of research and development activities, can be integrated into the development of a new product generation. E.g. functional concepts, which are completed in different degrees of maturity. This can be seen, for example, in the case of the machine tool development for punching head actuation with counter-shifting wedges.

- This basis consisting of current technical subsystems or objects from different sources can change during the development process. It can also be extended, especially through newly gained findings or newly received demands. An example is the requirement for the limited installation space of the tooling machine.

- There can be correlations like initial incompatibilities or undefined interfaces between these different technical subsystems or objects from different reference products, which represent the basis and starting point for development activities as these incompatibilities and interfaces have to be resolved and defined. The machine for foam production, which is supposed to combine new technology with a usual operator interface principles illustrates this.

- The different subsystems or objects, which represent the basis and starting point for the development of the structure and the subsystems of a new product generation can be subject to the control of different stakeholders. One example of this is the use of high-frequency and microwave technology systems by the manufacturer of the foam machines. This phenomenon presents parallels to the field of systems-of-systems.

- Subsystems and artefacts from existing systems can be used not only directly in the development of new product generations, but also indirectly, for example as a basis for strategy development. This is shown in the third case study.

In order to capture all the artefacts and their interrelations that actually form the basis of the development of a new product generation, the authors propose adding the element 'reference system' to the description model of the PGE, which is defined as follows:

The reference system for the development of a new product generation is a system whose elements originate from already existing or already planned socio-technical systems and the associated documentation and are the basis and starting point for the development of the new product generation.

Figure 2 illustrates the elements of the extended description model by another example. Reference system elements can come - if available -from the previous product generation. Furthermore, the elements of the reference system can also be subsystems from competitive products or subsystems of systems from other branches. Ultimately, prototypical solutions from the field of research can also serve as elements of the reference system. Since the development of a product, the development of a 
corresponding production system and the development of a validation system are all the development of a socio-technical system, the findings mentioned above also apply to the latter ones.

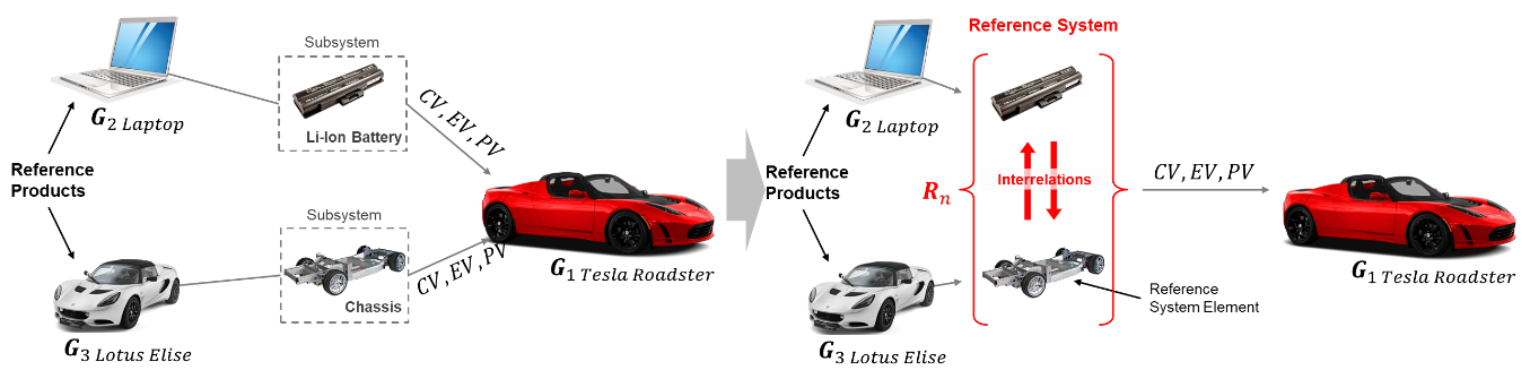

Figure 2: PGE model without and with the "reference system" using the Tesla Roadster as an example. Interrelations between subsystems: chassis needs to be adapted to the changed centre of mass; new operation condition for battery cells due to use in a vehicle. The reference system comprises those elements and their interrelations, which are the basis and starting point of the development activities for the new product generation. The development of the new product generation consists of the combination of carryover variation, embodiment variation and principle variation.

Furthermore, existing or planned socio-technical systems may also include business models or services. Already planned systems can, for example, be known in the form of initial specifications. For example, after the announcement of the planning of a new vehicle concept by a company, specifics such as acceleration or top speed can serve competitors as a reference for their own future vehicle generations.

The reference system represents the basis and starting point for future development activities. Based on the operation system of the product generation $\mathrm{Gi}$, the elements of the reference system are selectively transferred into the system of objects of the product generation Gi through the activities carryover variation, embodiment variation or principle variation.

The reference system changes constantly during the development process. However, this is not a selfdriven process. In fact, the reference system has to be actively put together and constantly developed.

Each product generation has its own reference system. In particular, if several product generations are being developed in parallel, the corresponding reference systems must also be developed in parallel. It is possible that elements occur in more than one reference system.

\section{CONCLUSION}

This contribution proposes the "reference system" as an additional element in the description model of PGE. This extension is motivated by the findings in the three cases. Consequently, these cases form the initial valid scope of application. Nevertheless, the proposed definition of the reference system contains no sector-specific characteristics so that it is assumed to be transferable to the product engineering in other examples. The modelling approach provided with the reference system should in particular fit to cases where the PGE model was already applied successfully, for example the case of the dual mass flywheel (Albers, Bursac and Rapp, 2016a).

The cases also give insights about observable interrelations between different reference system elements. However, no systematic of these relations can be derived here.

The PGE model with the reference system includes aspects, which are also part of other approaches and models, for example life cycle models, engineering change and others described in section 2 . Some of them might be depicted in more abstract way in the PGE model. The model of PGE with the reference systems aims at emphasizing the systemic character including the interrelations between different existing elements, which emerges by the intended common use as basis for a new product generation.

Mechanisms, which are similar to the ones described by the reference system can also be seen in the development of the system of objectives in product engineering. Objectives are often not formulated in an absolute way but in relation to and set apart from existing technical systems and their (presumed) system of objectives. The investigation of such phenomena is the subject of adjourning works.

\section{OUTLOOK}

The identification of potential elements of the reference system and their selection for the actual use in product engineering represent an important subject area. Connections to questions from the fields of 
patent and trend analysis as well as to the fields of product planning and foresight are to be expected here. While doing this, it is important to explain how the initial reference system of future product generations can be planned. Based on this, it is crucial to know how it is possible to continuously identify elements that should be added to the reference system. For this process, the comparison of the system of objectives of the currently developed product generation with the systems of objectives of potential elements of the reference system could be of importance. However, it is to expect that the actual system of objectives of a possible reference system element is not always directly available but has to be actively reconstructed. This can be the case in particular with reference system elements whose origin lies outside the company. Furthermore, the question arises as to how, correlations between characteristics of the reference system or its elements on the one hand, e.g. maturity, and variables such as development costs, risks, but also opportunities on the other hand can be understood and modelled, and to what extent prescriptive estimations are possible based on these correlations. Parallel to the investigation of these questions, the deduction of development activities based on the reference system can be investigated.

\section{REFERENCES}

Ahmed, S., Wallace, M. and Blessing, T. (2003), "Understanding the differences between how novice and experienced designers approach design tasks", Research in Engineering Design, Vol. 14, No.1, pp. 1-11.

Albers, A., Bursac, N. and Rapp, S. (2016a), "PGE-Product Generation Engineering-Case Study of the Dual Mass Flywheel", In: DS 84: Proceedings of the DESIGN 2016, 14th International Design Conference, pp. 791-800.

Albers, A., Bursac, N. and Wintergerst, E. (2015), "Product generation development-importance and challenges from a design research perspective", New Developments in Mechanics and Mechanical Engineering: proceedings of the International Conference on Mechanical Engineering, pp. 16-21.

Albers, A., Dumitrescu, R., Marthaler, F., Alexander, A., Kühfuss, D., Strauch, M., Siebe, A. and Bursac, N. (2018), "PGE-Produktgenerationsentwicklung und Zukunftsvorausschau: Eine systematische Betrachtung zur Ermittlung der Zusammenhänge”, 14. Symposium für Vorausschau und Technologieplanung (SVT), Berlin, Germany, 8-9 November 2018.

Albers, A., Reiß, N., Bursac, N. and Richter, T. (2016b), “iPeM - Integrated Product Engineering Model in Context of Product Generation Engineering”, Procedia CIRP, Vol. 50, pp. 100-105.

Alblas, A. and Jayaram, J. (2015), "Design resilience in the fuzzy front end (FFE) context: an empirical examination", International Journal of Production Research, Vol. 53, No. 22, pp. 6820-6838.

Arango, G., Schoen, E. and Pettengill, R. (1993), “A process for consolidating and reusing design knowledge Software Engineering", Proceedings of the 15th International Conference on Software Engineering, pp 231-242.

Corso, M., Muffatto, M. and Verganti, R. (1999), "Reusability and multi-product development policies: a comparison of approaches in the automotive, motorcycle and earthmoving machinery industries", Robotics and Computer-Integrated Manufacturing, Vol. 15, No. 2, pp. 155-165.

Cross, A. (2007), Engineering Design Methods - Strategies for Product Design, Wiley, Milton Keynes, UK.

Duffy, M., Duffy, A. H.B. and MacCallum, K., (1995), “A Design Reuse Model”, The Tenth International Conference on Engineering Design (ICED), Prague, 22-24 August, Heurista, Zurich.

Duffy, A.H.B. and Ferns, A. F., (1998), "An analysis of design reuse benefits", Proceedings of the 12th International Conference on Engineering Design (ICED '99), Design Society, pp. 799-804.

Eckert, C., John Clarkson, P. and Zanker, W. (2004), "Change and customisation in complex engineering domains", Research in Engineering Design, Vol. 15, No.1, pp. 1-21.

Eisa, H., Garstenauer, A. and Blackburn, T., (2018), "Causes of Engineering Change Propagation: An Analysis During Product Lifecycle”, Engineering Managment Journal, Vol. 30, No. 1, pp. 3-13.

Ettlie, E. and Kubarek, M. (2008), "Design Reuse in Manufacturing and Services”, Design Reuse in Manufacturing and Services, Vol. 25, No.5, pp. 457-472.

Fink, A., and SIEBE, A. (2016), Szenario-Management: von strategischem Vorausdenken zu zukunftsrobusten Entscheidungen, Campus Verlag, pp. 285-286.

Fleming, L. and Sorenson, O. (2001), "Technology as a complex adaptive system: evidence from patent data", Research Policy, Vol. 30, No. 7, pp. 1019-1039.

Gausemeier, J. and Plass, C., (2014), Zukunftsorientierte Unternehmensgestaltung: Strategien, Geschäftsprozesse und IT-Systeme für die Produktion von morgen, Hanser, Munich, Germany.

Gero, J., (1990), "Design prototypes: a knowledge representation schema for design", AI Magazine, Vol. 11, No. 4, pp. 26-36.

Hatchuel, A.; Le Masson, P. and Weil, B. (2004), “C-k Theory in practice : Lessons from Industrial Applications”, DS 32: Proceedings of DESIGN 2004, the 8th International Design Conference, Dubrovnik, Croatia, pp. 245-258. 
Hubka, V., Ernst and Eder, W., (1992); Einführung in die Konstruktionswissenschaft- Übersicht, Modell, Ableitungen, Springer-Verlag, Berlin Heidelberg, Germany.

Iyer, N., Jayanti, S., Lou, K., Kalyanaraman, Y. and Ramani, K. (2005), “Three-dimensional shape searching: state-of-the-art review and future trends", Compuer-Aided Design, Vol. 37, No. 5, pp. 509-530.

Jarratt, T., Eckert, C., Clarkson, P. J. and Schwankl, L., (2002), "Product Architecture and the Propagation of Engineernig Change", DS 30: Proceedings of DESIGN 2002, the 7th International Design Conference, Dubrovnik, pp. 75-80.

Jwa, (2018), "Revolution für Galaxy und iPhone: Samsung präsentiert unzerstörbares Display". [online] ntv. Available at: https://www.n-tv.de/technik/Samsung-praesentiert-unzerstoerbares-Displayarticle20546624.html (29.11.2018).

Kissel, M. and Lindemann, U. (2013): "System arrchitecture change decisions in multi-variant Product Portfolios", International Conference on Engineering Design, Seoul, Korea, 19-22 August 2013.

Langer, S., Maier, A. M., Wilberg, J., Münch, T. J. and Lindemann, U., (2012), "Exploring differences between average and critical engineering changes: Survey results from Denmark", DS 70: Proceedings of DESIGN 2012, the 12th International Design Conference, Dubrovnik, Croatia, pp. 223-232.

Maher, M. and Silva Garza, A. (1997), “Case-Based Reasoning in Design”, IEEE Expert: Intelligent Systems and Their Applications, Vol. 12, No. 2, pp. 34-41.

Markus, L (2001), "Toward a Theory of Knowledge Reuse: Types of Knowledge Reuse Situations and Factors in Reuse Success", Journal of Management Information Systems, Vol. 18, No. 1, pp. 57-93.

Marthaler, F., Orsolani, E., Uhlig, P., Kühlfuss, D.; Siebe, A., Bursac, N. and Albers, A. (2019), "Strategische Potentialfindung zur generationsübergreifenden Produktentwicklung mit langfristigem Zeithorizont: Eine qualitative Studie im Live-Lab IP - Integrierte Produktentwicklung”, 5. Stuttgarter Symposium für Produktentwicklung (SSP), Stuttgart, Germany, 16 May 2019.

Martin, M. and Ishii, K., (2002), "Design for variety: developing standardized and modularized product platform architectures", Research in Engineering Design, Vol. 13, No. 4, pp. 213-235.

Mozgova, I., Lachmayer, R. and Gottwald, P., (2015), "Formulations of Paradigms on technical Inheritance", In: Proceedings of the 20th International Conference on Engineering Design (ICED15), Politecnico di Milano, Italy, 27-30 July 2015.

Ropohl, G. (1975), Einführung in die Systemtechnik.: Systemtechnik - Grundlagen und Anwendungen, Carl Hanser Verlag, München.

Ruckpaul, A., Kriltz, A. and Matthiesen, S. (2014), “Using eye tracking to understand the engineering designers' behavior in synthesis-driven analyzing processes: experiences in study design", International conference on human behavior in design HBiD, Ascona, Switzerland, 14-17 October 2014.

Shahin T., Andrews P. and Sivaloganathan S. (1999), “A design reuse system”, Proceedings of The Institution of Mechanical Engineers Part B-journal of Engineering Manufacture, pp. 621-627.

Sivaloganathan S. and Shahin, M. (1999), "Design reuse: An overview", Proceedings of the Institution of Mechanical Engineers Part B Journal of Engineering Manufacture, pp. 641-654.

Wouters, M. J. F. and Kressens-van Drongelen, I. C. (2004), "Improving Cross-Functional Communication About Product Architecture", IEEE 2004 International Engineering Management Conference innovation and entrepreneurship for sustainable development, Singapore, 18-21 October 2004.

Wyatt, David, F., Eckert, Claudia M., Clarkson and P. John (2009), "Design of product architectures in incrementally developed complex products", DS58-4: Proceedings of ICED 09, the 17th Int. Conference on Engineering Design, Vol. 4, Product and Systems Design, Palo Alto, USA, 24-27 August 2009.

\section{PICTURE REFERENCES}

Figure 1: TRUMPF GmbH + Co. KG

Figure 2:

Laptop: CC BY-NC 4.0, (2016). Laptop Free Download PNG. [image] Available at: http://www.pngall.com/laptop-png/download/5419 [Accessed 19 Mar. 2019].

Laptop battery: Reichelt, (2019). AKKU_51136. [image] Available at: https://cdnreichelt.de/bilder/web/xxl_ws/D600/AKKU_51136.png [Accessed 19 Mar. 2019].

Lotus Elise: jct600, (2019). Elise. [image] Available at: https://www.jct600.co.uk/img/brands/lotus/newcars/thumbs/elise.png [Accessed 19 Mar. 2019].

Tesla Roadster: cars.com, (2019). [image] Available at: http://carpictures.cars.com/images/?IMG=USC10TSC011A0101.png\&WIDTH=624\&HEIGHT=300\&AUTOTRIM =1 [Accessed 19 Mar. 2019].

Elise Chassis: superstreetonline.com, (2019). [image] Available at: http://image.superstreetonline.com/f/31915428+w+h+q80+re0+cr1/modp_1002_03_o\%2Blotus_elise_alter native_project_car\%2Baluminum_chassis.jpg [Accessed 19 Mar. 2019]. 